\title{
Complete atrioventricular septal defect with tetralogy of Fallot: diagnosis and management
}

\author{
M A Gatzoulis, D Shore, M Yacoub, E A Shinebourne
}

\begin{abstract}
Objective-To report recent experience of patients with complete atrioventricular septal defect and tetralogy of Fallot, with emphasis on anatomical features, diagnosis, and management.

Design-Case notes were reviewed and patients were assessed at follow up by clinical examination and cross sectional and Doppler echocardiography.

Setting-Tertiary cardiothoracic referral centre.

Patients-Between 1987 and 199213 patients with atrioventricular septal defect and tetralogy of Fallot (12 with concordant and one with double outlet ventriculoarterial connections) underwent surgery; 10 underwent complete intracardiac repair. 11 patients had Down's syndrome. The complete diagnosis was established preoperatively by cross sectional echocardiography in all but one patient. A tri-leaflet left atrioventricular valve as seen in parasternal short axis views was the diagnostic feature of atrioventricular septal defect, with tetralogy of Fallot diagnosed from the presence of anterocephalad deviation of the outlet septum producing subvalvar pulmonary stenosis as seen in subcostal right anterior oblique views.
\end{abstract}

Interventions-Total correction consisted of closure of the atrioventricular septal defect by a combined right atrial and ventricular approach, reconstruction of the atrioventricular valves, and relief of the obstruction within the right ventricular outflow tract. Separate patches were used to close the atrial and ventricular septal defects. Modified BlalockTaussig shunts were performed in three patients, who await intracardiac repair. Surgical correction was carried out at mean (range) age of 5 (2 to 15) years.

Main outcome measures-Diagnostic methods, surgical results, and functional state after complete correction.

Results-The presence of an atrioventricular septal defect was missed preoperatively in one patient with tetralogy of Fallot. The characteristic goose neck deformity on the left ventriculogram was not present and the tri-leaflet nature of the left atrioventricular valve was not sought on echocardiography. Of the 10 patients who underwent complete repair, nine are alive and one died 34 days after operation with adult respiratory distress syndrome. Examination at necropsy showed an excellent surgical correction. Mean (range) follow up was 23 (8 to 48 ) months. All nine patients are alive and well (New York Heart Association Class 1).

Conclusion-Accurate diagnosis and staged management with improved surgical techniques have lowered mortality of this complex combination of cardiac defects. The current policy of this group is to recommend a systemic to pulmonary arterial shunt procedure for symptomatic children younger than 2 years and total correction in older children.

(Br Heart f 1994;71:579-583)

The combination of complete atrioventricular septal defect with tetralogy of Fallot is infrequent and has been reported to carry a high risk of death during complete correction. ${ }^{12}$ Improved understanding of the anatomy of this complex lesion, ${ }^{34}$ as well as its clinical recognition coupled with new surgical techniques ${ }^{56}$ have led to better results. We present our recent experience of morphological features, diagnosis, surgical management, and outcome of this rare combination.

Patients and methods

Between 1987 and 1992 we surgically treated 13 patients with complete atrioventricular septal defect and tetralogy of Fallot. The definition of tetralogy of Fallot was based on the anterocephalad deviation of the outlet septum in association with muscular subpulmonary stenosis. The ventriculoarterial connections were concordant in 12 patients and double outlet from the right ventricle in one. Ten patients underwent complete correction at a mean (range) age of 7·2 (2-15) years (median 5 year). A palliative systemic to pulmonary arterial shunt was constructed in the remaining three, who await total repair. There were nine boys and four girls. Eleven patients had Down's syndrome $(85 \%)$. A total of seven 
Table 1 Data on palliative procedures before complete repair

\begin{tabular}{lllll}
\hline & \multicolumn{2}{l}{ Age $(y r)$} & & \\
\cline { 2 - 3 } Diagnosis & At shunting & At repair & & Outcome \\
\hline AVSD, TOF, Down's & No shunts & 2 & Alive and well \\
AVSD, TOF, DORV, Down's & No shunts & $2 \cdot 7$ & Alive and well \\
AVSD, TOF, Down's & No shunts & $3 \cdot 5$ & Alive and well \\
AVSD, TOF, Down's & BT/0.9, BT/1·8 & 4 & Alive and well \\
AVSD, TOF, Down's & BT/1·2 & $5 \cdot 5$ & Alive and well \\
AVSD, TOF, Down's & No shunts & 6 & Died at 34 days (ARDS) \\
AVSD, TOF, Down's & No shunts & $8 \cdot 5$ & Alive and well \\
AVSD, TOF, Down's & BT/4, BT/7 & 10 & Alive and well \\
AVSD, TOF & WT/0.3 & 15 & Alive and well \\
AVSD, TOF & No shunts & 15 & Alive and well \\
AVSD, TOF, Down's & BT/0.3, BT/1·5 & - & Awaiting correction \\
AVSD, TOF, Down's & BT/1.3 & - & Awaiting correction \\
AVSD, TOF, Down's & BT/3.5 & - & Awaiting correction \\
\hline
\end{tabular}

AVSD, atrioventricular septal defect; ARDS, adult respiratory distress syndrome; BT, BlalockTaussig shunt; DORV, double outlet right ventricle; TOF, tetralogy of Fallot; WT, Waterston shunt.

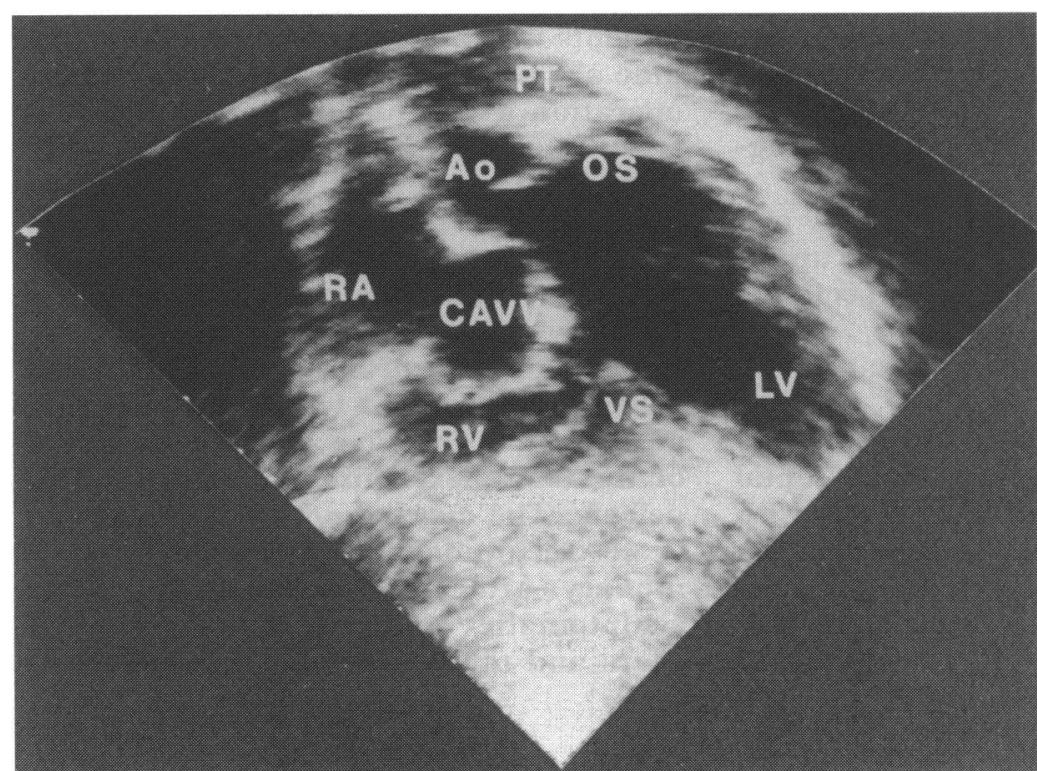

Figure 1 Subcostal right anterior oblique and coronal view: anterocephalad deviation of the outlet septum, producing subpulmonary infundibular stenosis. Also note the inlet to outlet disproportion of the left ventricle that combined with the horizontal/subaortic position of the superior bridging leaflet gives the characteristic goose-neck deformity. Ao, aorta; $C A V V$, common atrioventricular valve; $L V$, left ventricle; $O S$, outlet septum; $P T$, pulmonary trunk; $R A$, right atrium; $R V$, right ventricle; $V S$, ventricular septum.

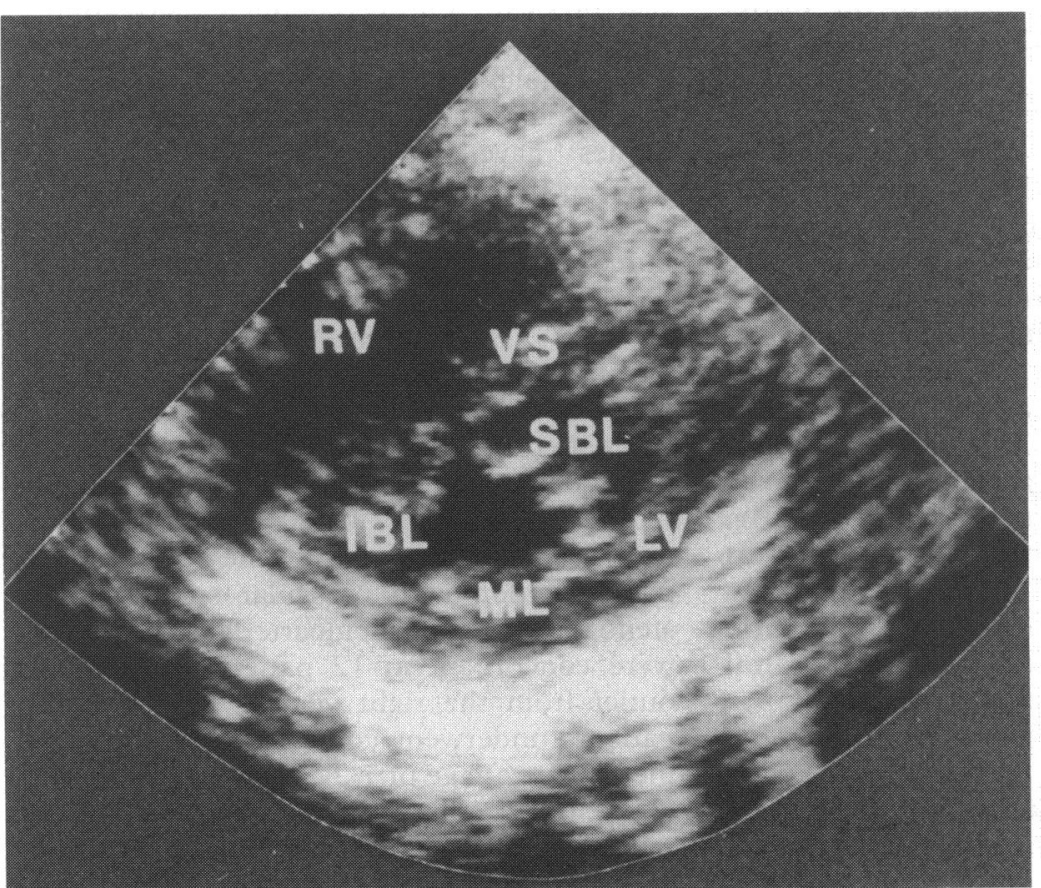

Figure 2 Short parasternal axis view: tri-leaflet left atrioventricular valve, consisting of the left sided portions of the superior and inferior bridging leaflets and the mural leaflet. $I B L$, inferior bridging leaflet; $M L$, mural leaflet, $S B L$, superior bridging leaflet; $L V$, left ventricle; $R V$, right ventricle; $V S$, ventricular septum. patients had one or more previous systemic to pulmonary arterial shunt (table 1 ).

Cyanosis with shortness of breath on exertion was evident in all 13 patients; eight had hypercyanotic attacks, necessitating urgent construction of systemic to pulmonary arterial shunts. Three patients were not thriving. One patient had a history of subacute bacterial endocarditis and one of convulsions associated with a cerebral abscess. All patients were in sinus rhythm. All but one had a superior mean (range) frontal QRS axis of $-80^{\circ}$ $\left(-40^{\circ}\right.$ to $\left.-120^{\circ}\right)$. First degree heart block was found in one patient, another had incomplete right bundle branch block. All patients had right ventricular hypertrophy. Plain roentgenography showed a right aortic arch in four, mild to moderate cardiomegaly in eight, a pulmonary arterial bay in six, and decreased pulmonary vascular marking in six patients.

Cross sectional echocardiography established the diagnosis in all but one patient. Anterocephalad deviation of the outlet septum with subpulmonary infundibular stenosis was seen in all patients in either the subcostal right anterior oblique or the short parasternal axis views (fig 1). The degree of aortic override, showing double outlet ventriculoarterial connection in one patient, was seen in the long and short parasternal axis views. The most constant feature of the atrioventricular septal defect was the trileaflet nature of the left atrioventricular valve as seen in the short parasternal axis view (fig 2). This feature was also present, as shown by postoperative review, in the patient in whom the diagnosis had initially been missed. Lack of off setting of the atrioventricular valves, cordal attachments of the left atrioventricular valve to the septum in the apical four chamber view, and unwedging of the aorta in the five chamber or long axis views also supported the diagnosis of atrioventricular septal defect. The presence of a common atrioventricular valve was best seen in the subcostal short axis view (fig 3).

All patients underwent cardiac catheterisation before complete correction. The characteristic goose neck deformity on the left ventriculogram was not present in the case in which the diagnosis had been missed. The pulmonary arteries were of good size with no distortion in all cases. The coronary arterial anatomy, more recently viewed angiographically in caudocranial, left anterior oblique view $^{7}$ (fig 4) was found to be normal in all patients. Mild atrioventricular valvar regurgitation was noted in four patients. The mean (range) transpulmonary pressure gradient was 59 (45 to 75 ) $\mathrm{mm} \mathrm{Hg}$.

Associated cardiovascular lesions included one patient with common atrium, one with a secundum atrial septal defect, two patients with persistent left superior vena cava draining to the coronary sinus, and one patient with a persistently patent arterial duct.

\section{OPERATIVE MANAGEMENT}

Ten patients underwent total repair under cardiopulmonary bypass and hypothermia to $25^{\circ} \mathrm{C}$ (or $20^{\circ} \mathrm{C}$ in younger patients with high collateral blood flow). As soon as bypass was 


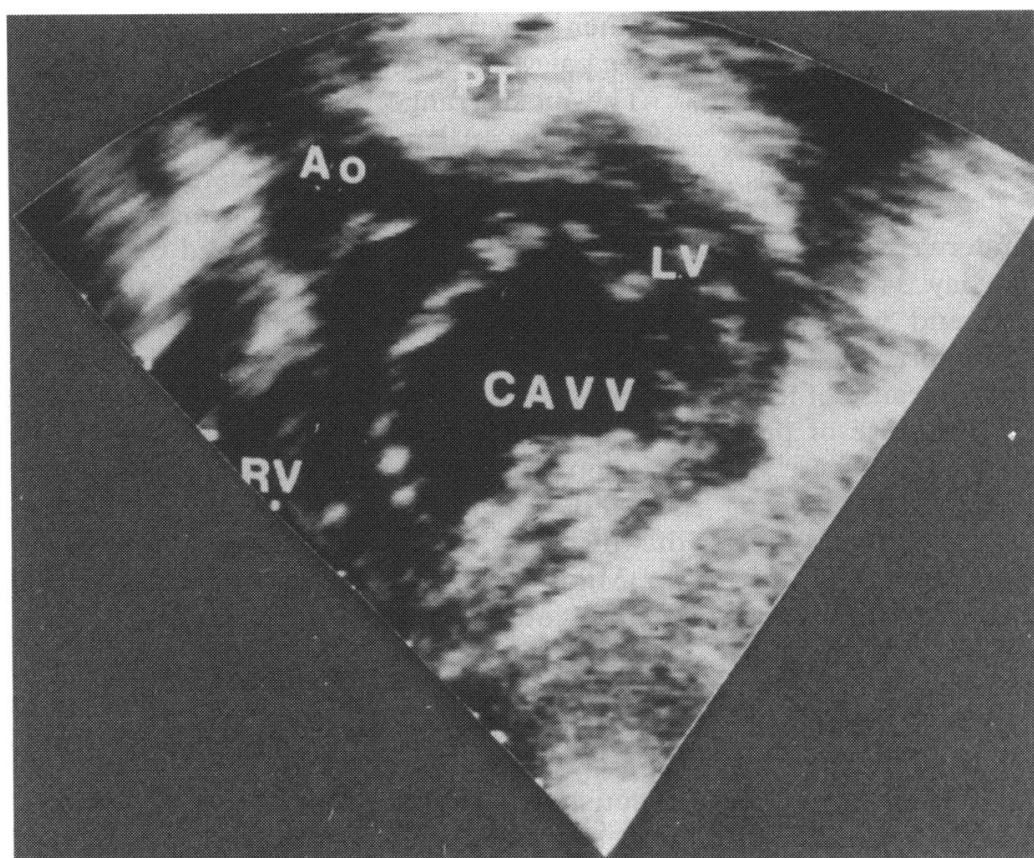

Figure 3 Subcostal short axis view: common atrioventricular valve in diastole. Note the overriding aorta in unwedged position. Ao, aorta; CAVV, common atrioventricular valve; $L V$, left ventricle; $P T$, pulmonary trunk; $R V$, right ventricle.

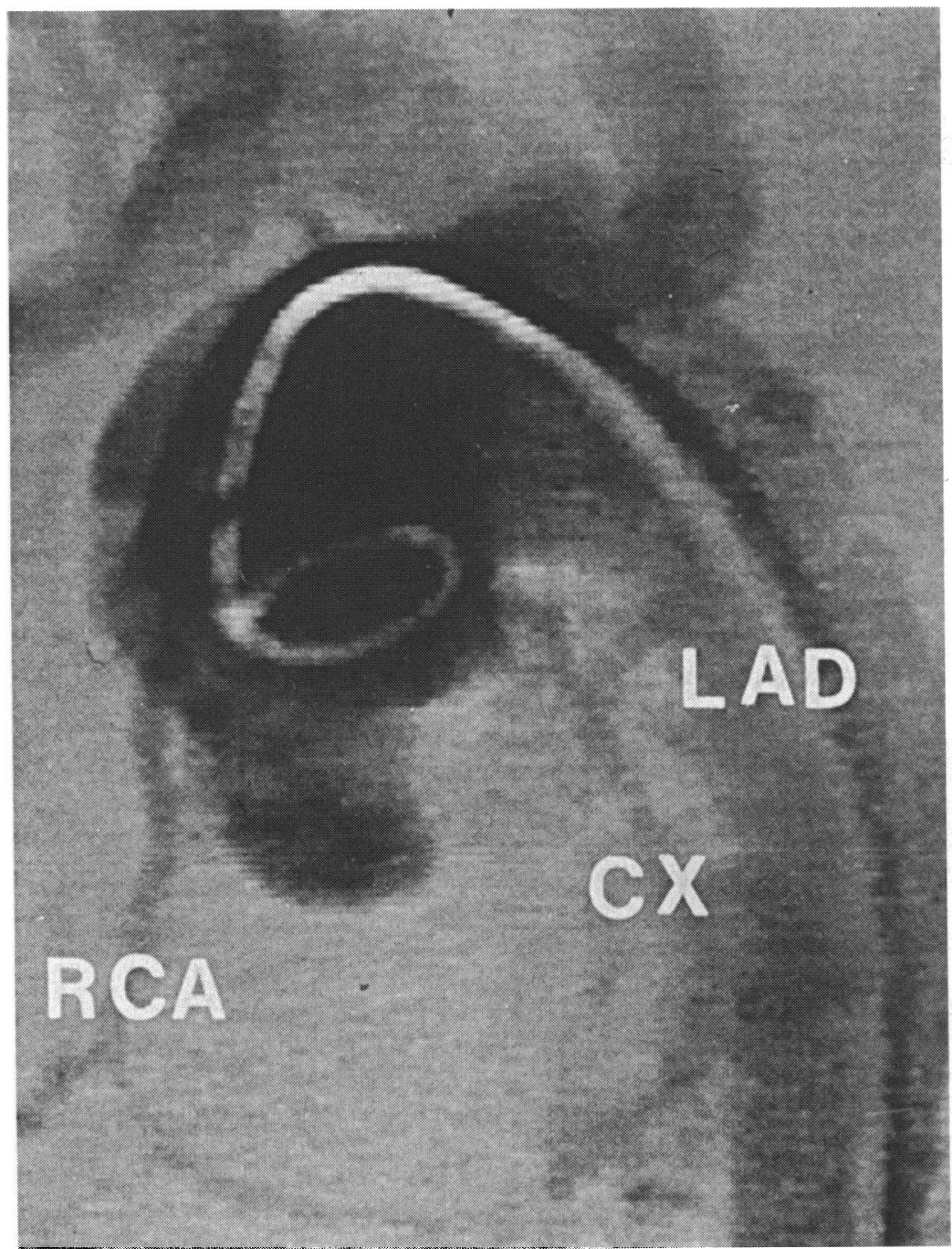

Figure 4 Ascending aortogram (anteroposterior) in $45^{\circ}$ caudocranial and $30^{\circ}$ left anterior oblique projection: normal coronary arteries. Note the absence of vessels across the right ventricular outflow tract, which excludes an anomalous origin of the left coronary artery. $C X$, circumflex; $L A D$, left anterior descending; $R C A$, right coronary artery.
Table 2 Right ventricular outflow tract relief or reconstruction in 10 patients with $A V S D$ and TOF who underwent complete repair

\begin{tabular}{ll}
\hline Type & $\begin{array}{l}\text { No of } \\
\text { patients }\end{array}$ \\
\hline Pulmonary valvotomy & 1 \\
Transannular patch (Gore-tex) & 1 \\
Monocusp pulmonary valve & 3 \\
Homograft valve & 2 \\
Subannular infundibular patch (Dacron) & 3 \\
Additional infundibulectomy & 8 \\
\hline
\end{tabular}

AVSD, atrioventricular septal defect; TOF, tetralogy of Fallot.

started, the Blalock Taussig shunts were ligated and, in the case of the Waterston shunt, the left and right pulmonary arteries were snared. Crystalloid cold cardioplegia (St Thomas's solution) and topical myocardial hypothermia were the protective methods routinely used. Intracardiac anatomy was inspected through a right atriotomy. All patients had a common atrioventricular valve. Eight patients had a free floating superior bridging leaflet (Rastelli type C). It was necessary to excise the primary component of the atrial septum in two cases to expose the left sided atrioventricular valve. The valve was tested for competence by injecting saline into the left ventricle. The point of coaptation between the superior and inferior bridging leaflets immediately above the crest of the ventricular septum was marked with sutures. The ventricular component of the septal defect was patched separately from the atrial component to facilitate valvar reconstruction. A non-porous patch appropriately trimmed was used in six cases (Dacron in four, Goretex in two), with a pericardial patch used in the remaining four. The patch was sutured on the right ventricular aspect of the ventricular crest with multiple interrupted sutures in the posteroinferior angle and then a continous suture along the rest of the inlet portion of the ventricular septal defect. Its anterosuperior extension was closed through a right ventriculotomy. Then the capacity of the right ventricular outflow was assessed and the obstruction relieved (table 2). Returning to the right atrial approach, interrupted mattress sutures were taken through the medial aspect of the patch used for closure of the ventricular component, placing them through the inferior and superior bridging leaflets and tying them over a patch of pericardium. The valve was made competent in all cases by a limited suture of the functional commissure between the two bridging leaflets. On retesting the valve with injection of saline it was found to be incompetent in one patient, necessitating annuloplasty at the commissure between the inferior bridging and the mural leaflets. Closure of the atrial component was completed with a pericardial patch in nine patients and an Impra patch in another. The right component of the superior bridging leaflet was then attached to the right aspect of the pericardial septum. The coronary sinus was left on the left side in all cases. In two cases, the pericardial patch was used as an intra-atrial baffle to redirect blood flow from a left superior caval vein. Finally, 
the aortic clamp was removed and the reconstruction of the right ventricular outflow tract (table 2) was completed.

\section{Results}

Of the 10 patients who underwent complete repair, one patient died on day 34; all other patients are currently alive and well. Four patients needed inotropic support when they were coming off bypass: three because of mild low cardiac output and one because of profound vasodilatation. All patients were in sinus rhythm. A transient junctional tachycardia occurred later in one patient, and two patients underwent early reoperation because of moderate but persistent postoperative haemorrhage. Intracardiac pressures, measured in the operating theatre soon after repair, showed a mean (SD) right ventricular pressure of 41.2 (12) $\mathrm{mm} \mathrm{Hg}$ with a left ventricular pressure of $82 \cdot 1(13.3) \mathrm{mm} \mathrm{Hg}$ and a mean right to left ventricular pressure ratio of $0 \cdot 52$.

Prolonged ventilation was required for three patients, all with Down's syndrome, and of these patients two had lower respiratory tract infections, one due to Klebsiella pneumoniae and the other probably due to Candida albicans, based on high antigen titres. The third patient developed the clinical picture of adult respiratory distress syndrome, further complicated on day 14 after operation with sepsis and coagulopathy. $\mathrm{He}$ was the one patient to die (on day 34), because of progressive unresponsive pulmonary disease. At post mortem examination, the anatomical correction was found to be excellent. The newly constructed atrial and ventricular septums were intact and there was adequate relief of the obstruction within the right ventricular outflow tract. No obstruction was found in the left ventricular outflow tract, but inspection of the left atrioventricular valve showed small friable vegetations, not seen on cross sectional echocardiography. All cultures remained sterile throughout the postoperative period. Also, one patient with Down's syndrome needed reintubation on two occasions because of upper airway obstruction, and another patient had a transient right phrenic nerve palsy.

The mean (range) follow up was 23 ( 8 to 48) months. All nine patients are alive and well (New York Heart Association class I). They are all pink, free of symptoms, and have good exercise tolerance. As judged by clinical examination, cross sectional echocardiography and colour Doppler interrogation, two patients have mild left atrioventricular valvar regurgitation and another two have trivial pulmonary regurgitation with no evidence of progression at present. Small residual ventricular septal defects were found in two patients, one of which had closed spontaneously on follow up. Mild residual obstruction of the right ventricular outflow tract was found in two patients, but no patients had left ventricular outflow tract obstruction.

\section{Discussion}

The combination of atrioventricular septal defect with tetralogy of Fallot, although uncommon, should be easy to recognise because of its obvious morphological features. The diagnosis should be suspected in any patient with tetralogy of Fallot and Down's syndrome, as atrioventricular septal defect occurs commonly in trisomy $21 .{ }^{8} \mathrm{~A}$ superior mean frontal QRS axis on the surface electrocardiogram (in all but one of our 13 patients) in patients with tetralogy of Fallot is also strongly suggestive of the combined lesion.

Cross sectional echocardiography, in our experience, is the definitive imaging technique with which to establish the diagnosis. The trileaflet left atrioventricular valve was always seen in the parasternal short axis view, even in the one case where the complete diagnosis was initially not recognised. The valve consists of the left sided portions of the superior and inferior bridging leaflets, with the commissure between them pointing toward the inlet of the left ventricle, together with the mural (or left lateral) leaflet, which is noticeably shorter and in a different position from that found in a normal mitral valve with two leaflets. ${ }^{9}$ It is of note that these features are still apparent after successful repair (fig 5). An
Figure 5 Short parasternal axis views before (left) and after (right) successful repair on the same patient. The trileaflet nature of the left atrioventricular valve is readily recognisable, even after its surgical reconstruction (right). $L V$, left ventricle; $R V$, right ventricle; $V S$, ventricular septum. $I B L$, inferior bridging leaflet; $M L$, mural leaflet; $S B L$, superior bridging leaflet.

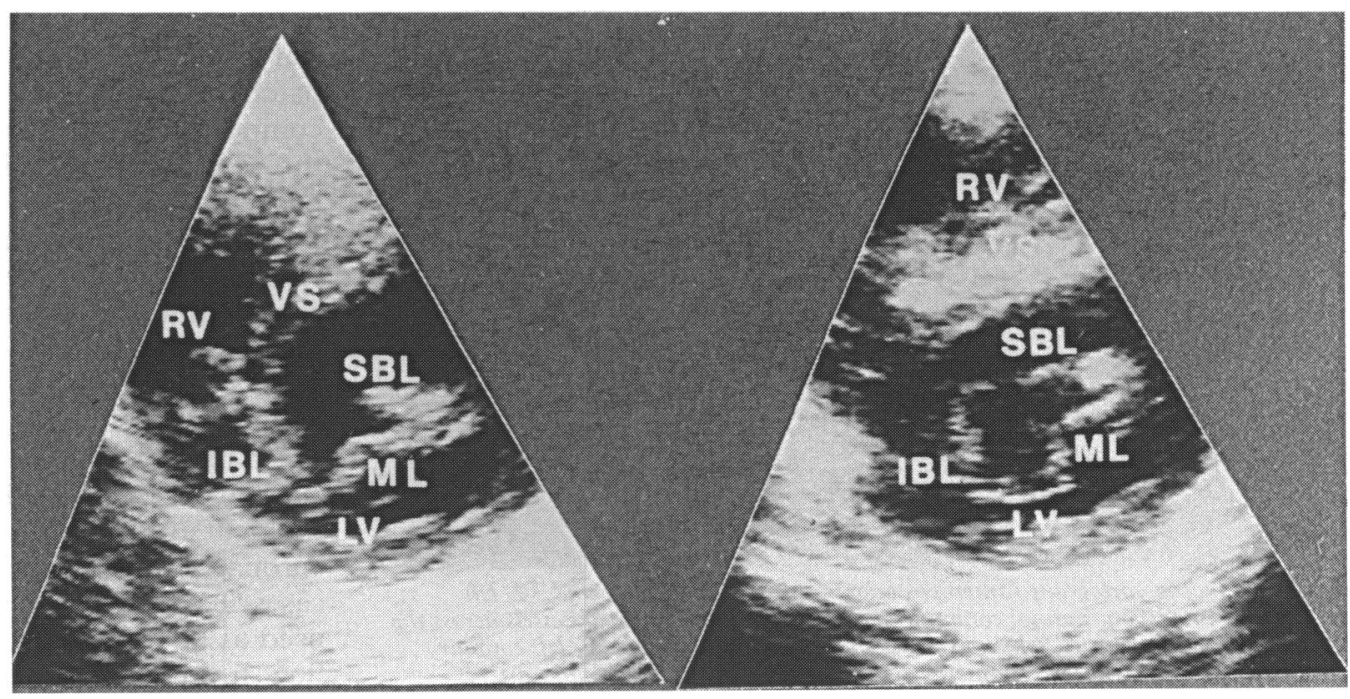


unwedged aorta, best seen in the subcostal long axis view, and giving rise to an elongated left ventricular outflow tract, was also constantly present. Other supportive, but not pathognomonic, findings are the lack of offset of the atrioventricular valves and cordal attachments of the left atrioventricular valve to the ventricular septum. The presence of a common valve is better assessed in subcostal coronal views. The diagnosis of tetralogy of Fallot was made in all patients by showing the anterocephalad deviation of the outlet septum coupled with subvalvar (infundibular) pulmonary stenosis. These features were most clearly seen in either the subcostal right anterior oblique or parasternal short axis views. The degree of aortic override was seen in the parasternal long and short axis views. In one case, more than half of the circumference of the aorta was connected within the right ventricle, and so the ventriculoarterial connection was designated as double outlet right ventricle. Colour flow Doppler imaging shows the shunting patterns and the presence and degree of atrioventricular valvar regurgitation.

All patients underwent angiography before complete correction. The diagnosis was evident in all but one patient, where the characteristic goose neck deformity was not present. Left and right ventriculograms showed ventricles of adequate size, no additional ventricular septal defects, good size pulmonary arteries in all 10 patients, and mild atrioventricular valvar regurgitation in four. The coronary arteries, "more recently screened in $45^{\circ}$ caudocranial and $30^{\circ}$ left anterior oblique projection ${ }^{7}$ were all of normal pattern.

Of the 13 patients, 11 had Down's syndrome (84\%). All 13 patients had a common atrioventricular valve. By Rastelli's classification, 11 had a free floating superior bridging leaflet (type $\mathrm{C}$ ), as opposed to type B or minimal bridging, which is seen in most patients with Down's syndrome and atrioventricular septal defect alone. ${ }^{10}$ Other features often seen with this combination of defects are a well developed primary atrial septum and a small ventricular septal defect beneath the inferior bridging leaflet that is commonly obscured by multiple cords. ${ }^{11}$ When undertaking surgical correction, both occasionally require excision to improve exposure of the left atrioventricular valve and the posterior inferior angle of the ventricular septal defect. These manoeuvres allow adequate inspection and reconstruction of the left atrioventricular valve, safe placement of sutures, and avoidance of damage to the conduction tissue.

The well established combined atrial and ventricular approach was used in all patients, providing excellent access to the left ventricular outflow and, therefore, safe closure of this portion of the defect. A single patch, appropriately trimmed, was used to close the confluent ventricular septal defect in all but one patient. No obstruction was found in the left ventricular outflow tract. Particular attention was paid to the reconstruction of the right ventricular outflow tract to avoid more than mild pulmonary valvar incompetence, as this may be poorly tolerated in these often very hypertrophied hearts.

There is uncertainty about the need for palliation and the optimal time for complete repair. ${ }^{12}$ Our three youngest patients underwent correction at $2,2 \cdot 7$, and 3.5 years without previous palliation. The decision was made on social grounds (desire for definite correction in a child with Down's syndrome) in all three cases and, despite their young age, the outcome was excellent. This finding, although not statistically significant, raises the question as to whether earlier complete repair is preferable. The obvious advantages of this against palliative procedures is to prevent volume loading of the left ventricle and development or progression of atrioventricular valvar regurgitation or ventricular hypertrophy. In the current era of precise preoperative diagnosis and advanced surgical techniques, it is possible that anatomical correction in infancy carries a smaller risk than previously reported. ${ }^{16}$

Our current approach is for early palliation in symptomatic infants when there is a history of cyanotic episodes, severe cyanosis, or hypoplastic pulmonary arteries, and of complete correction after infancy when the anatomy is favourable.

We conclude that definitive diagnosis of atrioventricular septal defect with tetralogy of Fallot can be made on cross sectional echocardiography alone and successful surgical repair carried out in early childhood.

We thank Professor R H Anderson for his helpful comments during preparation of this paper.

1 Uretzky G, Puga F, Danielson G, Feldt R, Julsrud P, Seward J, et al. Complete atrioventricular canal associated with tetralogy of Fallot. F Thorac Cardiovasc Surg 1984;87:756-66.

2 Vogel M, Sauer U, Buhlmeyer K, Sebening F. Atrioventricular septal defect complicated by right venAtrioventricular septal defect complicated by right ven-
tricular outflow obstruction. $\mathcal{F}$ Cardiovasc Surg 1989;30: 34-9.

3 Anderson RH, Baker E, Ho SY, Rigby ML, Ebels T. The morphology and diagnosis of atrioventricular septal morphology and diagnosis of atriovent

4 Ho SY, Anderson RH. The modern assessment of tetralogy of Fallot: morphological aspects. La Chir Torac 1990;43:101-10

5 Arciniegas E, Hakimi M, Farooki Z, Green E. Results of total correction of tetralogy of Fallot with complete atrioventricular canal. If Thorac Cardiovasc Surg 1981;81 768-73.

6 Alonso J, Nunez P, Perez de Leon J, Sanchez P, Villagra F Gomez $\mathrm{R}$, et al. Complete atrioventricular canal and tetralogy of Fallot: surgical management. Eur $\mathcal{f}$ Cardiothorac Surg 1990;4:297-9.

7 Carvalho JS, Da Silva MC, Rigby ML, Shinebourne EA. Angiographic diagnosis of anomalous coronary artery in tetralogy of Fallot. Br Heart f 1993;70:75-8.

8 Baciewicz FA, Melvin W, Basilius D, Davis J. Congenital heart disease in Down's syndrome patients: a decade of heart disease in Down's syndrome patients. a decade of surgical

9 Anderson RH, Ebels T, Zuberbuhler J, Silverman N. The left valve in atrioventricular septal defect-anatomic and echocardiographic features. In: Anderson R, Neches W, Park S, Zuberbuhler J, eds. Perspective in paediatric

10 Silverman N, Zuberbuhler J, Anderson RH. Atrioventricular septal defects: cross sectional echocarAtrioventricular septal defects: cross sectional echocardiographic and mort

11 Vargas F, Coto E, Mayer J, Jonas R, Castaneda A. Complete atrioventricular canal and tetralogy of Fallot: surgical considerations. Ann Thorac Surg 1986;42. 258-63

12 Sade RM, Riopel D, Lorenzo R. Tetralogy of Fallot associated with complete atrioventricular canal. Ann Thorac Surg 1980;30:177-80. 